\title{
How accurately can surface markers be placed on bony landmarks of the foot?
}

\author{
Alpesh Kothari', Julie Stebbins ${ }^{1 *}$, Jessica Leitch ${ }^{2}$, Amy Zavatsky ${ }^{2}$ \\ From 3rd Congress of the International Foot and Ankle Biomechanics Community \\ Sydney, Australia. 11-13 April 2012
}

\section{Background}

The use of multi-segment foot models is becoming increasingly popular during clinical gait analysis. While numerous studies have established the repeatability of these models, the accuracy is more difficult to determine since measuring motion of the bones is a challenging task. One assumption influencing model accuracy is that

Table 1 Reliability for identifying landmarks

\begin{tabular}{ll}
\hline & $\mathbf{9 5 \%}$ confidence interval \\
\hline Intra-observer $(n=3)$ & $0.19 \mathrm{~mm}-0.37 \mathrm{~mm}$ \\
Inter-observer $(n=3)$ & $0.21 \mathrm{~mm}-0.57 \mathrm{~mm}$ \\
\hline
\end{tabular}

surface markers can be placed precisely over palpated, bony landmarks. The aim of this study is to test this assumption by assessing marker placement using CT scans.

\section{Materials and methods}

Twenty female subjects (forty feet) participated in this study. All subjects had ECG electrodes attached to their lower limbs according to the positions required by the Oxford Foot Model [1]. Positioning was performed by a single tester on all subjects. Subjects lay supine in the CT scanner, in a semi-weight-bearing position using a custom-built rig. The anatomical landmarks and the

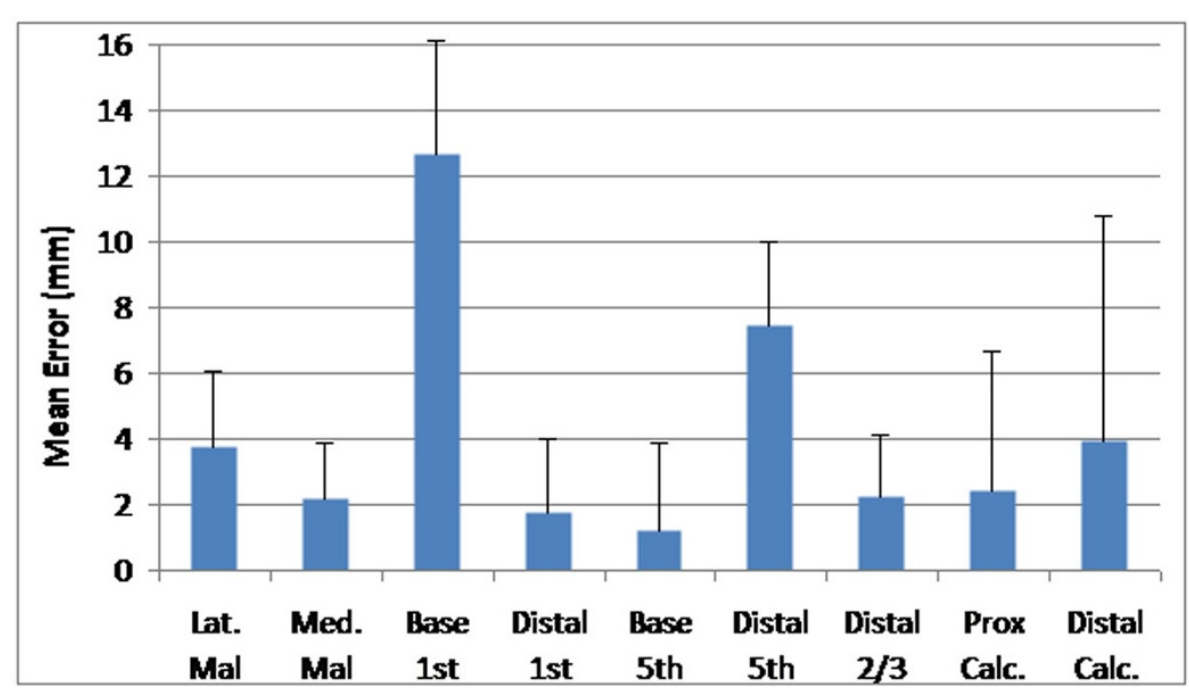

Figure 1 Mean error (mm) across all feet for all markers

* Correspondence: julie.stebbins@noc.nhs.uk

${ }^{1}$ Nuffield Orthopaedic Centre, Oxford, OX3 7LD, UK

Full list of author information is available at the end of the article 
positions of the markers were identified on the scans using a pre-defined protocol. Intra- and inter-rater reliability were assessed. Marker placement accuracy was determined by assessing relevant components of the distance between markers and bony landmarks.

\section{Results}

Good intra- and inter-rater reliability was demonstrated for identifying markers on the CT images (Table 1). The average distance between bony landmarks and marker positions differed according to position on the foot (Figure 1). The mean error was lowest for the base of $5^{\text {th }}$ metatarsal marker $(1.2 \mathrm{~mm})$ and highest for the base of $1^{\text {st }}$ metatarsal $(12.7 \mathrm{~mm})$. There was a systematic offset for this marker, due to slight differences in definition for placing the marker on the skin, and identifying the bony landmark on CT images. Of the nine marker positions analysed, seven markers had a mean error of less than $5 \mathrm{~mm}$.

\section{Conclusions}

Surface markers can be placed accurately over bony landmarks on the foot; however, some positions can be more precisely palpated than others. This should be taken into account when interpreting results from multi-segment foot models.

\section{Author details}

${ }^{1}$ Nuffield Orthopaedic Centre, Oxford, OX3 7LD, UK. ${ }^{2}$ Department of

Engineering Science, University of Oxford, Oxford OX1 3PJ, UK.

Published: 10 April 2012

\section{Reference}

1. Stebbins J, Harrington M, Thompson N, Zavatsky AB, Theologis T: Repeatability of a model for measuring multi-segment foot kinematics in children. Gait Posture 2006, 23:401-4.

doi:10.1186/1757-1146-5-S1-040

Cite this article as: Kothari et al:: How accurately can surface markers be placed on bony landmarks of the foot? Journal of Foot and Ankle Research 2012 5(Suppl 1):040

\section{Submit your next manuscript to BioMed Central} and take full advantage of:

- Convenient online submission

- Thorough peer review

- No space constraints or color figure charges

- Immediate publication on acceptance

- Inclusion in PubMed, CAS, Scopus and Google Scholar

- Research which is freely available for redistribution

Submit your manuscript at www biomedcentral.com/submit 